\title{
Spectrin Beta Chain, Non-Erythrocytic 2
}

National Cancer Institute

\section{Source}

National Cancer Institute. Spectrin Beta Chain, Non-Erythrocytic 2. NCI Thesaurus. Code C106020.

Spectrin beta chain, non-erythrocytic 2 (2390 aa, $\sim 271 \mathrm{kDa}$ ) is encoded by the human SPTBN2 gene. This protein plays a role in the regulation of actin filament function. 